\title{
A docência na educação de jovens e adultos: limites e possibilidades da atuação docente
}

\author{
Laís Bastos Marchesoni ${ }^{1}$ \\ Viviane Gislaine Caetano Auada ${ }^{2}$ \\ Elsa Midori Shimazaki ${ }^{3}$
}

\begin{abstract}
Resumo
As possibilidades de atuação do professor na alfabetização e na escolarização de jovens e adultos não alfabetizados, que retornam ou ingressam ao ambiente escolar pela modalidade de Educação de Jovens e Adultos, constitui o tema central da pesquisa relatada. Por meio de uma pesquisa bibliográfica, o artigo discute as possibilidades de atuação docente e o seu papel não apenas no que se refere ao ensino de conceitos científicos, mas, também, no aspecto social em que os educandos buscam emancipação e participação efetiva em sociedade, por meio da escolarização. O estudo possibilita verificar que o docente tem papel fundamental na educação de jovens e adultos, tanto na mediação do conhecimento científico, como na apresentação de um compromisso ético e social com esses educandos.
\end{abstract}

Palavras-chave: EJA; Docência; Cidadania.

Teaching in young people and adult education: limits and possibilities of the teaching activity

\section{Abstract}

The main theme of current research is the possibility of the teacher working with literacy and schooling of illiterate young people and adults who return to school to procedure in their studies. Current bibliographic research discusses the possibilities of teachers' activities and their role not merely in the transmission of scientific concepts but also in the social issue in which these people try to achieve emancipation and effective participation in society, through schooling. Current paper underscores teachers' basic role in the education of young people and adults within the mediation of scientific knowledge and in the ethical and social commitment with students of the specific modality. Keywords: EJA; Teaching; Citizenship.

\section{Introdução}

Este artigo ${ }^{4}$ trata da Educação de Jovens e Adultos (EJA), definida como uma modalidade de ensino da educação brasileira que contempla o atendimento a pessoas que não conseguiram realizar ou concluir os estudos do Ensino Básico na idade estipulada legalmente como adequada (BRASIL, 1996). Esta modalidade de ensino atende às necessidades dos educandos, a respeitar

\footnotetext{
${ }^{1}$ Universidade Estadual de Maringá, Maringá, lais_marquesoni@hotmail.com

2 Universidade Federal do Pará, Belém, vcaetano@ufpa.br

${ }^{3}$ Universidade do Oeste Paulista, Presidente Prudente e Universidade Estadual de Maringá, Maringá, elsa@unoeste.br

${ }^{4} \mathrm{O}$ texto é fruto de pesquisa relatada na dissertação de mestrado produzida pela primeira autora.
} 
as características de cada indivíduo, oportunizar o regresso à sala de aula de maneira a adequar os estudos às suas condições de vida e de trabalho, assim como a seus interesses, por meio de cursos e exames próprios. A EJA é uma modalidade de ensino presencial, que atende jovens, adultos e idosos, a partir dos quinze anos de idade, para o ensino fundamental, e dezoito anos de idade ou mais para o ensino médio. Os educandos matriculados podem não estar alfabetizados ou, até mesmo, não terem concluído os anos iniciais do ensino fundamental, a mostrar o objetivo de continuar ou concluir os seus estudos (BRASIL, 2006).

A Lei de Diretrizes e Bases da Educação Nacional (LDB), Lei 9.394/96, em seu Capítulo II, seção $V$, no artigo 37, estabelece que "A educação de jovens e adultos será destinada àqueles que não tiveram acesso ou oportunidade de estudos no ensino fundamental e médio" (BRASIL, 1996, p.30). Ao ser estabelecida na LBD, a EJA possibilitou maior acesso e possibilidade de estudos para quem não pôde estudar em outro momento da vida (BRASIL, 1996). A Lei fortalece a obrigatoriedade do Estado em oferecer o acesso à população a tal modalidade educacional, com condições de funcionamento adequadas e de qualidade, para que se cumpram os objetivos de cidadania, inclusão social e melhoria da qualidade de vida pessoal e profissional dos educandos envolvidos. Além da alfabetização, a modalidade de ensino amplia as oportunidades de jovens, adultos e idosos no âmbito social e na participação da cidadania, a acrescentar-lhes as habilidades de letramento sociais, dentre eles, o escolar (BRASIL, 1996).

As diretrizes contempladas na EJA são: superação do analfabetismo; universalização do atendimento escolar; superação das desigualdades educacionais, com ênfase na promoção da cidadania e na superação de todas as formas de discriminação; melhoria da qualidade da educação; formação para o trabalho e para a cidadania, com ênfase nos valores morais e éticos em que se fundamenta a sociedade (BRASIL, 1996). Dessa forma, verificamos que ela não se limita apenas à alfabetização e a apropriação de outros conteúdos escolares, como também abrange questões sociais determinadas.

As Diretrizes Curriculares Nacionais para a Educação de Jovens e Adultos (DCNEJA) afirmam que a EJA é um direito do cidadão, independente do nível de escolarização (BRASIL, 2000). A sua oferta é dever dos estados e municípios, sendo obrigatoriamente ofertada no ensino regular e na estrutura curricular do ensino fundamental e médio. No mesmo documento, consta que a EJA considerará situações específicas da modalidade, os perfis dos estudantes, as faixas 
etárias e pautar-se-á pelos princípios de equidade, diferença e proporcionalidade, a respeitar a igualdade de direitos e oportunidades, as diferenças e as necessidades próprias da EJA, inclusive de programas de inclusão (BRASIL, 2000).

Além da oferta do ensino fundamental e do ensino médio, é possível a integração da EJA a cursos da educação profissional, a possibilitar ao educando alcançar o nível de ensino desejado, acrescido de uma qualificação profissional para atuar no mercado de trabalho. A procura por este tipo de oferta é maior, uma vez que muitos educandos, que já trabalham ou que almejam trabalhar, buscam um ensino profissionalizante a auxiliar e ampliar a formação profissional (BRASIL, 2006). Dessa forma, questões profissionais estão presentes na modalidade e são consideradas no trabalho educativo.

O Plano Nacional de Educação (2014-2024) propõe a elevação da taxa de alfabetização da população com quinze anos de idade ou mais para 93,5\% até o final de 2024. Também objetiva acabar com o analfabetismo absoluto ${ }^{5}$ e reduzir em $50 \%$ a taxa de analfabetismo funcional ${ }^{6}$, com isso, leva a oferecer, no mínimo, $25 \%$ das matrículas à EJA no ensino fundamental e no médio, na forma integrada à educação profissional (BRASIL, 2014). Esse objetivo de erradicação do analfabetismo tem, na educação escolar, um importante mecanismo, em que se amplia e possibilita a jovens e adultos o acesso ao conhecimento científico e sistematizado, na escola.

Ainda sobre a questão do analfabetismo destacamos que os termos que a classificação do tipo de analfabetismo que se encontram os indivíduos é utilizado em documentos escritos e publicados pelo governo, que não vão ao encontro de muitas questões que envolvem o analfabetismo, se caracterizando como um classificador e se distancia da realidade histórica e social dos jovens e adultos que não utilizam a leitura e a escrita no seu cotidiano por não terem se apropriado delas. Dessa forma ao referir-se ao analfabetismo precisa considerar as características sociais, culturais e históricas. Há muitas pessoas que mesmo sem ou com pouco domínio da leitura e da escrita convivem na sociedade letrada atendendo as suas demandas;

\footnotetext{
${ }^{5} \mathrm{O}$ analfabetismo absoluto refere-se ao indivíduo que recebeu pouca ou nenhuma instrução para ler e escrever e realizar cálculos fundamentais, a ser incapaz de, até mesmo, escrever o próprio nome, na maioria das vezes. É um grupo de indivíduos que se identifica mais facilmente, dadas as sua características peculiares, bem como se pode quantificar estatisticamente (BRASIL, 2018).

${ }^{6} \mathrm{O}$ analfabetismo funcional refere-se ao indivíduo que, apesar de ter frequentado a escola, não possui autonomia para utilizar os conhecimentos de leitura e escrita que adquiriu no cotidiano, com eficiência adequada (BRASIL, 2018).
} 
dessa forma, a questão no analfabetismo absoluto é um fator questionável e deve ser pensado profundamente.

Corroboramos com Pinto (1982) que afirma que o analfabeto não se caracteriza como o indivíduo que não sabe ler, mas aquele que na sua condição concreta de existência, não necessita da leitura e da escrita. Para o autor, o que determina a necessidade que o sujeito tem de ser alfabetizado é o trabalho que ele exerce, dessa forma, são as situações reais da vida do indivíduo que irão levá-lo ou não à busca de uma formação escolar. Para o autor, esse é o enfoque que deve ser considerado ao definir o grau de analfabetismo de uma pessoa, ou seja, são as questões particulares e individuais que são determinantes (PINTO, 1982).

Com a democratização do ensino, o que se observa, ao longo das últimas décadas, são ações que visam garantir o acesso e a permanência dos educandos na escola. Contudo, essas ações não são desenvolvidas de maneira efetiva a originar um novo panorama da educação brasileira. Conforme afirmam Haddad e Di Pierro (2000),

A ampliação da oferta escolar não foi acompanhada de uma melhoria das condições do ensino, de modo que, hoje, temos mais escolas, mas sua qualidade é muito ruim. A má qualidade do ensino combina-se à situação de pobreza extrema em que vive uma parcela importante da população para produzir um contingente numeroso de crianças e adolescentes que passam pela escola sem lograr aprendizagens significativas e que, submetidas a experiências penosas de fracasso e repetência escolar, acabam por abandonar os estudos. Temos agora um novo tipo de exclusão educacional: antes as crianças não podiam frequentar a escola por ausência de vagas, hoje ingressam na escola, mas não aprendem e dela são excluídas antes de concluir os estudos com êxito (HADDAD; DI PIERRO, 2000, p.125-126).

Nesse sentido, o contexto que se tem é de uma sociedade formada por um grande número de indivíduos que, mesmo tendo frequentado a escola, não conseguiram desenvolver as competências e as habilidades necessárias para utilizar os conhecimentos adquiridos de maneira apropriada em seu cotidiano. Assim, "O resultado desse processo é que, no conjunto da população, assiste-se à gradativa substituição dos analfabetos absolutos por um numeroso grupo de jovens e adultos cujo domínio precário da leitura, da escrita e do cálculo vem sendo tipificado como analfabetismo funcional" (HADDAD; DI PIERRO, 2000, p.126), muitas das vezes são esses jovens e adultos que procuram a EJA, em busca de melhorias sociais, em vários aspectos. 
De acordo com a Base Nacional Comum Curricular (BRASIL, 2017), o currículo escolar deve ser orientado pelos princípios éticos, políticos e estéticos que, traçados pelas Diretrizes Curriculares Nacionais da Educação Básica (BRASIL, 2013), direcionam a educação brasileira para a formação humana integral e para a construção de uma sociedade justa, democrática e inclusiva para o pleno desenvolvimento da educação e a garantia do direito dos educandos a aprender e a se desenvolver, contribuindo, assim, para o desenvolvimento pleno da cidadania. Em síntese, esse conjunto de competências explicita o compromisso da educação brasileira com a formação humana integral (BRASIL, 2017).

Nessa perspectiva traçada, a EJA, no Brasil, é amparada por leis e documentos citados, assim como é estabelecida pela LDB (BRASIL, 1996), que define suas características a ofertar, e a estabelecer a obrigatoriedade e o direito de acesso ao ensino sistematizado a todo cidadão que não teve oportunidade de estudar anteriormente, ou que não concluiu os seus estudos. A EJA, nesse contexto, é um mecanismo atuante e qualificado, não apenas para alfabetizar cidadãos, como também na busca por uma sociedade igualitária que possibilite a maior participação de todos.

Além disso, as leis estabelecem o cumprimento de algumas necessidades dessa modalidade específica de ensino, por exemplo, cidadania, qualificação ou integração profissional, oportunidades, ética, formação humana, justiça e igualdade. Dessa forma, ao explicitarmos sobre a EJA compreendemos sua importância no contexto educacional e na sociedade letrada em que vivemos, pois a alfabetização e a escolarização vão além do conhecimento científico, pois se caracterizam como um mecanismo social. Nesse contexto, a prática docente define-se com um importante papel. Para tanto, discutimos, neste texto, o trabalho do professor na EJA em vários aspectos, não somente no papel de alfabetizador, como, também, de participante ativo nas questões sociais dos seus educandos.

O interesse pela temática se tornou relevante à medida que o desejo dos educandos pela apropriação de conhecimentos que permitissem uma melhor e maior atuação social eram tão genuínos quanto a busca por conhecimentos escolares. Dessa forma, o presente artigo apresenta uma pesquisa bibliográfica, na qual buscamos pesquisas sobre o tema abordado em periódicos e livros para melhor entendimento da temática. Compreendemos que a pesquisa em Educação está relacionada, de acordo com Ludke; Andé (1986, p.34) a “[...] um processo emancipatório na 
construção de um sujeito histórico, participante e crítico", dessa forma a pesquisa é necessária em qualquer estudo, para que se chegue a um maior entendimento e compreensão do objeto que está sendo estudado.

Os estudos que tematizam o EJA são rarefeitos e, não são estáticos e absolutos, como qualquer outra pesquisa, todavia a investigação possibilita melhor compreensão do tema. Para Vygotsky (1996) é necessário estudar o homem nas relações sociais, pois ele não é apenas um produto da evolução biológica é também produto do desenvolvimento histórico e cultural.

Desta forma, escrevemos o presente artigo que objetiva discutir o papel do professor na EJA e as suas possibilidades de atuação, tanto no que se refere ao ensino científico e à transmissão de conhecimento quanto nas questões sociais, como a emancipação e a participação efetiva dos educandos em sociedade por meio da escolarização.

\section{Os educandos da EJA: a perspectiva docente}

São muitos fatores que levam um indivíduo a interromper os estudos, sejam eles trabalho, problemas familiares, negligência, repetência etc. Cada sujeito traz um histórico de vida em sua bagagem cultural, que deve ser considerado pelo docente no trabalho escolar.

Para um trabalho educativo de qualidade torna-se importante compreender o perfil do estudante da EJA, conhecer a sua trajetória de vida, a cultura e os costumes, principalmente o que o levou a não estudar ou interromper seus estudos, sobretudo entender a não homogeneidade do grupo e os estudantes como sujeitos plurais de experiências e vivências diversas. A LDB (BRASIL, 1996) aponta que o educando da EJA constrói o conhecimento mediante a compreensão dos processos de trabalho, de criação, de produção e de cultura, e passa a se reconhecer como sujeito do processo e a confirmar saberes adquiridos para além da educação escolar, na própria vida (BRASIL, 1996). Nessa perspectiva, o trabalho escolar precisa ser significativo e compreendido pelo educando da EJA, e o professor, nesse contexto, tem papel fundamental, pois, ao trabalhar com essa modalidade específica, é necessário considerar a diversidade que se constitui nas diferenças entre os estudantes, com "[...] mulheres, homens, crianças, adolescentes, jovens, adultos, idosos, pessoas com necessidades especiais, indígenas, afrodescendentes, entre outros. A diversidade que constitui a sociedade brasileira abrange jeitos 
de ser, viver, pensar - que se enfrentam" (BRASIL, 2008, p.1).

Portanto, a diversidade também está presente na EJA. Quantas histórias, identidades e diferenças há na sociedade escolar e no âmbito educacional que dialogam em uma sala de aula da EJA, a considerar o "[...] direito garantido pela Constituição de ser diferente" (BRASIL, 2008, p.1). Questionamos, então, quem é o estudante da EJA? Qual é o seu perfil? Qual é a sua representação social? Para buscar resposta, retomamos Schwartz (2012) ao afirmar que "As representações sociais constituem no senso comum dos indivíduos, elaborado a partir de imagens, crenças, mitos e ideologias. Contribui para os processos de formação de condutas e de orientação das comunicações sociais" (SCHWARTZ, 2012, p.61). Neste caso, para a autora, o jovem, o adulto e o idoso que voltam a estudar são vistos pela sociedade em uma perspectiva negativa e preconceituosa. Essas representações sociais podem causar sentimentos de medo e incapacidade nos educandos. O professor, neste caso, contribui para a desmistificação dessa visão a valorizar o educando e seus conhecimentos. Oliveira (1999) afirma que o educando da EJA “[...] não é o estudante universitário, o profissional qualificado que frequenta cursos de formação continuada ou de especialização, ou a pessoa adulta interessada em aperfeiçoar seus conhecimentos em áreas como artes, línguas estrangeiras ou música, por exemplo" (OLIVEIRA, 1999, p.59).

A população atendida pelo EJA são pessoas que deixaram ou não frequentaram a escola e citamos como causas: a falta acesso a uma escola próxima da sua casa para iniciar ou continuar a educação escolar; a necessidade de inserção precoce no trabalho formal ou não; as mudanças continuas de residência; as vulnerabilidade sociais de pessoas que moram em áreas rurais ou urbanas empobrecidas; migrantes e imigrantes; moradores de rua, pessoas com deficiência ou transtornos funcionais específicos; mulheres; dentre outras (MARCHESONI, 2019).

Ainda sobre o jovem e o adulto inseridos na EJA, verificamos que eles podem ter sido excluídos do ambiente escolar, anteriormente, por diversos fatores, como o impedimento pela família de acesso à escola, questões econômicas e sociais, trabalho infantil etc., geralmente a se caracterizar como um trabalhador, que tem responsabilidades provenientes da vida adulta, tudo isso necessita ser considerado na prática docente.

Outra característica importante dos educandos da EJA é que cada um traz sua bagagem cultural, não se constituindo, assim, um grupo homogêneo de pessoas, porque pertencem a 
diferentes grupos sociais, com peculiaridades intelectuais, sociais, emocionais diferentes, fatores que também devem ser considerados no trabalho do professor como um todo. Nas classes escolares há diferenças individuais que distinguem as pessoas em seu modo de responder as demandas de seu contexto de vida cotidiana. Dessa forma, "[...] não há uma correlação positiva entre o nível de escolaridade dos sujeitos e os conhecimentos apreendidos na escola" (OLIVEIRA, 1999, p.72).

Assim, no ambiente escolar, no currículo e no processo de ensino-aprendizagem, o conhecimento precisa fazer sentido e motivar o sujeito, porque estudar nem sempre é uma tarefa fácil ou prazerosa, ainda mais na fase adulta. Di Pierro, Joia e Ribeiro $(2001$, p.75) reforçam ao defender que deve haver "[...] motivação para que todos continuem aprendendo, e que a necessidade e a vontade de aprender são inerentes a todos os seres humanos, do nascimento à velhice". Assim, na escola, o educando se sentiria motivado e estimulado a novas aprendizagens.

Os fatores que interferem na motivação do estudante são diversos, como o ambiente escolar, o professor, as questões pessoais, a falta de envolvimento do educando com a aprendizagem, entre outras. Martinelli (2014) apresenta o conceito de motivação realizada pelo professor, em que acredita que influenciaria os educandos de uma forma positiva, o qual tem se mostrado correlacionada ao desempenho acadêmico de estudantes positivamente. Para a autora, "[...] a motivação do docente interfere consideravelmente no desempenho escolar dos educandos por realçar o comportamento de aprendizagem e de realização dos indivíduos, tais como escolher tarefas, prestar atenção, despender esforços e demonstrar persistência" (MARTINELLI, 2014, p.212).

Ainda sobre a motivação do estudante jovem e adulto realizada pelo professor, Schwartz (2012, p.72) aponta que o trabalho pedagógico seria “[...] justificado e significado, e constantemente buscar o prazer e a melhoria para a qualidade de vida que ela pode trazer, apontando diariamente os avanços e as conquistas". Assim, a motivação oferecida pelo professor, no contexto da EJA, é indispensável, pois, além das peculiaridades próprias da idade, o educando apresenta dificuldades no processo de aprendizagem e na compreensão dos conteúdos escolares por estar afastado dos estudos por um longo período de tempo, o que necessita da mediação direta do docente.

Ferreiro (2015) defende que, de todos os grupos populacionais, as crianças são as mais 
fáceis de serem alfabetizadas. Já os adultos sentem mais dificuldades no processo de alfabetização. As especificidades do processo de aprendizagem dos educandos adultos precisam ser planejadas adequadamente para que garantam êxito em sua execução (FERREIRO, 2015). Essas elaboração e aplicação de conteúdos precisam ser planejadas adequadamente pelo docente, como base nos conhecimentos que os alunos já trazem e o que necessitam aprender como conhecimento escolar.

Essa tarefa pode ser complexa. Para tanto, Di Pierro, Joia e Ribeiro (2001, p.72) recomendam "[...] flexibilizar currículos, meios e formas de atendimento, integrando as dimensões de educação geral e profissional" (DI PIERRO; JOIA; RIBEIRO, 2001, p.72), os autores complementam ao afirmar que, para que isto aconteça, é necessário que sejam formulados “[...] projetos pedagógicos pertinentes as necessidades educativas das comunidades em que estão inseridos" (2001, p.72) e também o provimento de "[...] múltiplas ofertas de meios de ensinoaprendizagem, presenciais ou a distância, escolares ou extra-escolares" (DI PIERRO; JOIA; RIBEIRO, 2001, p.72), com isso, possibilita "[...] aperfeiçoar os mecanismos de avaliação, diversificando e flexibilizando os meios de acesso a níveis de escolaridade mais elevados" (DI PIERRO; JOIA; RIBEIRO, 2001, p.72). De acordo com a afirmação dos autores, entendemos que o trabalho do professor seria repensado e adaptado às necessidades dos educandos a que se destina, sempre primando em proporcionar a elaboração de conhecimentos significativos e eficazes na busca pela garantia da igualdade e da superação das injustiças sociais agregadas a esses sujeitos.

Outra questão a ser considerada pelo professor refere-se às diferenças entre estudantes crianças e estudantes adultos. Oliveira (2007, p.83) afirma que "[...] na educação de jovens e adultos ocorre a infantilização dos educandos ou inadequação de conteúdos e modos de abordálos". Assim, torna-se necessário atender as necessidades dos educandos e adequar os conteúdos e as metodologias a cada faixa etária, a diferenciar educandos crianças de educandos jovens e adultos, a tornar o ensino significativo e adequado para todos.

Oliveira (1999) afirma ainda que há uma falta de conexão entre o trabalho da escola e as necessidades dos educandos, pois estes podem sentir um possível desconforto em não ter estudado quando eram crianças, a sentirem-se deslocados do grupo e, até mesmo, evadirem-se da escola. Além das causa citada pela autora, acrescentamos que a falta de acesso aos bens 
materiais, as jornadas extenuantes de trabalho, a baixa remuneração pelos trabalhos realizados, isto é, a péssima divisão de rendas têm gerado e aumentado as desigualdades sociais e tem sido o principal fator da exclusão social.

Para Freire (1982), a questão do analfabetismo é uma situação produzida socialmente, ou seja, que se perpetua pelas relações de poder e opressão que subjugam as massas da população. O analfabetismo é um fator social, advindo de situações que abrange questões econômicas, culturais e de classe. Essas situações têm relação com a exclusão social, na qual educandos jovens e adultos não tiveram acesso a escolarização por diversos processos excludentes, como a pobreza, a falta de recursos, a falta de intrução dos pais etc. Fatos recorrentes em uma sociedade que exclui os menos favorecidos e não lhes garantem o acesso e permanência aos conhecimentos historicamente acumulados.

Segundo Maciel (2011), a abordagem freireana está voltada para a população marginalizada e socialmente excluída, que, em muitos casos, caracterizam os educandos da EJA. Nesse sentido, sua pedagogia se volta para a conscientização das massas do sistema de opressão a que estão submetidas. É necessário que o professor entenda que o seu aluno possui um saber atribuído de sua própria história, que, muitas vezes, não é valorizado e até excluído do conhecimento historicamente acumulado, dentro do sistema escolar. Por isso, torna-se necessário "[...] se construir uma educação a partir do conhecimento do povo e com o povo, provocando uma leitura da realidade na ótica do oprimido, que ultrapasse as fronteiras das letras e se constitua nas relações históricas e sociais" (MACIEL, 2011, p.328) para que, assim, o ensino seja formativo e tenha viés social efetivo.

Dessa forma, o trabalho educativo tem conexão com as necessidades de aprendizagem dos educandos, a fim de que permaneçam e prossigam em seus estudos, a evitar, assim, a desistência, fato comum na modalidade da EJA.

Além de todas essas adequações, é importante considerar o conhecimento dos educandos, suas experiências e aprendizagens, ou seja, sua bagagem cultural. Os estudantes da EJA pertencem a diferentes grupos sociais, tendo peculiaridades intelectuais, sociais, emocionais etc. Esses fatores são levados em consideração no trabalho do professor. Assim, todo conhecimento trazido pelos educandos faria parte do trabalho escolar e fortaleceria o vínculo com a aprendizagem. 
Outra característica importante é o papel social dos educandos da EJA. De acordo com Andrade (2004, p.1), esses estudantes "[...] ainda são vistos com relação ao fracasso escolar, tratados, a priori, como os repetentes, evadidos, defasados, aceleráveis, deixando de fora dimensões da condição humana desses sujeitos, básicas para o processo educacional". Tais visões podem ser combatidas no trabalho docente em uma perspectiva que amplie as possibilidades dos educandos e os proporcione mais do que a transmissão dos conteúdos, mas uma efetiva construção social. Shimazaki e Cárnio (2011) discutem que pessoas com pouca escolaridade seriam socialmente excluídas, porém, a escola pode ampliar as possibilidades de exercer a cidadania e participar ativamente na sociedade. Assim, a escolarização proporcionaria aos educandos uma ampliação nos seus aspectos sociais.

Nesse sentido, compreendemos que o estudante da EJA traz especificidades e busca na escola não apenas a alfabetização, como também a cidadania e a sua melhoria de vida. Para tanto, torna-se necessário superar concepções errôneas e preconceituosas, por exemplo, de que a idade adequada para aprender é quando se é criança e de que a EJA é a reposição de escolaridade perdida na infância. Dessa forma, a educação para jovens e adultos responde às necessidades formativas dos seus estudantes, a visar tanto a formação educativa em si quanto a qualificação profissional, a buscar a formação de sujeitos “[...] livres, autônomos, críticos, abertos à mudança, capazes de intervir em processos de produção cultural que tenham alcance político" (DI PIERRO; JOIA; RIBEIRO, 2001, p.74).

Para Freire (1979, p.35), “[...] não há educação fora das sociedades humanas e não há homens isolados. O homem é um ser de raízes e espaços temporais". Além disso, os educandos trazem marcas de luta e resistência obtidas em sua trajetória de vida, nas quais são explícitas no trabalho educativo e escolar.

\section{Função social da educação de jovens e adultos: o papel do professor}

Ao longo da história, a EJA vem sendo oferecida para corrigir uma falha do sistema com educandos que não estudaram quando crianças. A partir dessa premissa, o professor da EJA, "Deve ultrapassar o enfoque de educação compensatória, em favor de uma visão mais ampla e permanente" (ANDRADE, 2004, p.1-2). 
A EJA demonstra aspectos que são próprios dessa modalidade de ensino, por exemplo, as especificidades da faixa etária dos educandos e as dificuldades e desafios de quem iniciou ou voltou a estudar depois de um tempo fora do ambiente escolar, como a idade, o trabalho, a família etc. Para Durante (1998, p.13), a alfabetização de jovens e adultos é “[...] um campo complexo porque envolve questões além do educacional, relacionadas à situação de desigualdade socioeconômica em que se encontra grande parte da população do nosso país". A questão social está presente em todas as modalidades de ensino, em vários aspectos, e precisa ser contemplada no trabalho do professor e relacionada à prática educacional.

Di Pierro, Joia e Ribeiro (2001, p.70) argumentam que "[...] a demanda pela educação de jovens e adultos é extensa e complexa, comportando em seu interior uma grande diversidade de necessidades formativas", a indicar as peculiaridades dessa modalidade de ensino, que necessita de um olhar próprio e específico. Além da alfabetização, o professor deve considerar os requisitos formativos para o exercício da cidadania, as exigências pela qualificação e as demandas culturais dos grupos de alunos atendidos (FREIRE, 2001).

Sabemos que a alfabetização é fundamental para os educandos jovens, adultos e idosos nas práticas escolares, porém, além de alfabetizar, a EJA tem como base o compromisso com a formação humana e com o acesso à cultura, pois, de acordo com as DCNs ela deve trabalhar de forma que "[...] os educandos aprimorem sua consciência crítica, e adotem atitudes éticas e compromisso político, para o desenvolvimento da sua autonomia intelectual" (BRASIL, 2006, p.27), a fornecer, assim, subsídios para que se afirmem como sujeitos ativos, participantes, críticos, criativos e democráticos.

Segundo Dias et al. (2011, p.50), “[...] cabe destacar que os sujeitos aos quais se destinam o fazer pedagógico da EJA têm outras especificidades que ultrapassam a condição de não criança, baixa escolaridade e integrante das camadas populares", por exemplo, o trabalho que deve ser considerado no processo de aprendizagem da EJA. Por se tratarem de educandos trabalhadores, as suas identidades são formadas pelas experiências do meio em que vivem e se relacionam, inclusive, nas relações no mundo do trabalho. Portanto, os conteúdos abordados pelos professores estarão articulados à realidade e ao cotidiano dos educandos, a abranger sua dimensão sócio-histórica, articulada ao mundo do trabalho, à ciência, às tecnologias etc. Sobre o educando e suas peculiaridades, Paiva (2009) comenta que 
Os trabalhadores que se constituíram como tais pelo trabalho, e por esta via se constituíram cidadãos, questionam-se sobre um futuro incerto, duvidoso, e frequentemente admitem que a insegurança é culpa individual, pela baixa escolaridade, pela pouca 'educação'. No entanto, como trabalhadores constituem suas vidas, família, prole, educaram seus filhos, exerceram a cidadania, ensinando o mesmo valor que os constituiu, embora na prática, nem para si próprios, os valores estejam sendo mantidos (PAIVA, 2009, p.70).

O trabalho realizado por esses educandos tem papel fundamental em suas vidas, particularmente por suas condições sociais e, muitas vezes, é por meio dele que retornam à escola e nela permanecem. O trabalho também “[...] valoriza questões culturais, que podem ser potencializadas na abertura de espaços de diálogo, troca, aproximação, resultando interessantes aproximações entre jovens e adultos" (ANDRADE, 2004, p.3). Assim, verificamos que os ofícios realizados pelos estudantes precisam fazer parte da prática educativa como um mecanismo aproximador dos conteúdos escolares e da vida cotidiana.

Para superar o distanciamento das práticas escolares com a realidade e atender as reais necessidades dos educandos, torna-se fundamental que o professor compreenda o sentido da escolarização na vida do jovem e do adulto. Sobre isso, Kuenzer (2002) aponta algumas questões que são trabalhadas na EJA, e contemplam a sua função social:

Aprender permanentemente; refletir de modo crítico; agir com responsabilidade individual e coletiva; participar do trabalho e da vida coletiva; comportar-se de forma solidária; acompanhar a dinamicidade das mudanças sociais; enfrentar problemas novos construindo soluções originais com agilidade e rapidez, a partir do uso metodologicamente adequado de conhecimentos científicos, tecnológicos e sócio-históricos (KUENZER, 2002, p.40).

O trabalho docente na EJA contempla diversos aspectos do educando, a tornar o ensino formativo, a contemplar as diferentes culturas, política, cidadania, situação socioeconômica, as ocupações e a motivação pelas quais os jovens e adultos procuram a escola. Assim, o educando passa a ser visto como um sujeito inserido em um contexto social, histórico e cultural, com conhecimentos adquiridos em experiências vividas. Nesse sentido, o ensino contemplaria conteúdos significativos, em uma perspectiva de significação de concepção de mundo, de si mesmo e dos conhecimentos científicos. Além disso, o trabalho escolar estaria articulado às 
necessidades, expectativas e trajetórias de vida dos educandos. Sobre a função social da EJA, a LDB aponta que a educação abrange os processos formativos que se desenvolvem na "[...] vida familiar, na convivência humana, no trabalho, nas instituições de ensino e pesquisa, nos movimentos sociais e organizações da sociedade civil e nas manifestações culturais" (BRASIL, 2000 , p.8). Dessa forma, a educação escolar será efetiva ao vincular-se ao mundo do trabalho, assim como as demais práticas sociais.

Nesse contexto, a escola é um espaço privilegiado para desenvolver habilidades, pensamento crítico, reflexão e novos conhecimentos. Também é o lugar a propiciar a socialização dos sujeitos, a autonomia intelectual e o incentivo para que continuem e avancem em seus estudos, consequentemente, na melhoria de sua qualidade de vida. De acordo com Dias et al (2011, p.69), é preciso “[...] considerar a concepção do processo educativo como uma formação que se dá ao longo da vida e, nessa perspectiva, valida a ideia de que tal processo não deve estar restrito às etapas regulares da escolarização", ou seja, o professor precisa considerar que o educando jovem e adulto continue a aprender e avançar em seus conhecimentos para além do ambiente escolar, ou seja, em sua vida social.

Nesse bojo das discussões, Durante (1998, p.49) explica que, “[...] além de estarem aprendendo, os educandos da EJA vivenciam relações de amizade, adquirem autoestima, valorização dos próprios conhecimentos, do esforço pessoal e partilham com outros seus aprendizados". Assim, para atender todas essas necessidades dos educandos aqui presentadas, não basta oferecer uma educação de qualidade, faz-se necessária uma educação que esteja vinculada a mudanças na qualidade de vida, nos aspectos sociais, econômicos, políticos e culturais dos indivíduos. Portanto, o trabalho docente, nesse campo específico da educação, contribui para a formação de cidadãos autônomos e críticos, a realizar mudanças, contribuir para a emancipação humana e o exercício de uma cidadania democrática com base em valores, como respeito mútuo, solidariedade e justiça, para que, assim, o acesso, a permanência e o sucesso do educando estejam assegurados, a manter a melhoria e a qualidade do ensino nas escolas (FREIRE, 2001). A partir dessas constatações, verificamos a necessidade de reflexão do docente sob sua prática educativa, que contemple também aspectos sociais. 


\section{O trabalho do docente como uma questão social}

A discussão sobre a EJA é uma questão não somente escolar, mas, também, essencialmente social. De acordo com Freire (1982), a alfabetização vai além do conhecimento das letras e números, pois implica numa tomada de consciência dos sistemas opressores e, a partir dela, se rebelar de forma coletiva e libertária para buscar a construção de uma sociedade mais justa e igualitária. Dessa forma, o trabalho docente vai além de apenas "alfabetizar", uma vez que se trata de um trabalho de conscientização e cidadania.

Na perspectiva da educação popular voltada para os excluídos, Freire (1982) afirma a importância do ato de aprender a ler para além dos bancos escolares. Justamente aí se encaixa a sua concepção sobre a alfabetização de jovens e adultos:

Inicialmente me parece interessante reafirmar que sempre vi a alfabetização de adultos como um ato político e um ato de conhecimento, por isso mesmo, um ato criador. Para mim seria impossível engajar-me num trabalho de memorização mecânica dos ba-be-bi-bo-bu, dos la-le-li-lo-lu. Daí também que pudesse reduzir a alfabetização ao ensino pura da palavra, das sílabas ou das letras. Ensino em cujo processo o alfabetizador fosse "enchendo" com suas palavras as cabeças supostamente "vazias" dos alfabetizandos. Pelo contrário, enquanto ato de conhecimento e ato criador, o processo da alfabetização tem, no alfabetizando, o seu sujeito (FREIRE, 1982, p.13).

O autor define a alfabetização para adultos em uma visão crítica e assume a conscientização e a cultura como categorias e base de sua argumentação. Entende que a educação, que é uma atividade humana, a ser realizada pelo professor, tem, em si mesma, a capacidade de minimizar a alienação e conscientizar os educandos que estão nesse processo.

A alfabetização, então, deve se realizar por meio do processo educativo e também da socialização, a considerar a educação escolar e a social, em complementos necessários. É importante que o professor compreenda que o adulto que busca a alfabetização traz consigo uma história de vida e suas experiências sociais, o que não pode ser ignorado, mas, sim, valorizado na construção de um sujeito político e participativo. De acordo com Freire (2001), jamais se separa a realidade do educando do ensino e do trabalho docente, pois, por meio da realidade é que se busca a transformação democrática da sociedade, a superação das injustiças 
sociais e o respeito à posição de classe dos educandos, sem que isso interfira em sua prática ou que a torne assistencialista. Nesse contexto, o professor é o sujeito que trabalha, objetivando a qualidade do ensino e os índices de aprovação por meio da aquisição da linguagem, do ensino da escrita e da leitura de forma crítica e participativa (FREIRE, 2001).

De acordo com Freire (2001, p.89), "[...] do ponto de vista crítico e democrático, o alfabetizando e não o analfabeto se insere num processo criador, de que ele é também sujeito". Para o autor, o adulto não volta à escola apenas para ser alfabetizado, ou seja, para ler e escrever, mas, também, para suprir outras necessidades, por exemplo, exercer sua cidadania. 0 objetivo do professor então é propiciar ao educando a apropriação das práticas de linguagem instauradas na sociedade para que possam ter participação social efetiva. Freire (2001) sinaliza, ainda, que a aprendizagem acontece na troca de conhecimentos, pois, enquanto o educando aprende, também ensina; e o professor, quando ensina, também aprende; assim ambos transformam e são transformados em um processo educativo contínuo. Desta forma, além de ensinar o educando a ler e a escrever, o professor, no ensino para jovens e adultos, busca levar acesso ao conhecimento e à cidadania.

Além de transmitir os conteúdos historicamente construídos aos indivíduos, é importante também valorizar competências e habilidades já adquiridas fora da escola, em outros contextos sociais que não o escolar. Para Freire (1996, p.52), é importante “[...] saber que ensinar não é transferir conhecimento, mas criar as possibilidades para a sua própria produção ou a sua construção", implicando, assim, em possibilidades de melhorias concretas na vida dos indivíduos.

Desta feita, valorizar os conhecimentos que os educandos já apresentam em seu cotidiano é de suma importância. Sobre esse fato, Freire $(1996$, p.15) orienta professores a "respeitarem os saberes dos educandos, sobretudo os das classes populares, saberes socialmente construídos na prática comunitária" e complementa sugerindo "[...] discutir com os educandos a razão de ser de alguns desses saberes em relação com o ensino dos conteúdos", isto significa aproveitar a experiência dos educandos, fazendo com que possam relacionar sua vida com os conteúdos escolares, em suma, que o ensino tenha significado para eles.

Nessa posição de pensamento, Visca (2008, p.7) afirma que "A aprendizagem abre o caminho da vida, do mundo, das possibilidades, até de ser feliz", pois a aprendizagem vai muito além do aprendizado sistemático dos conteúdos, já que possibilita uma mudança de vida e novas 
condições sociais. Como educadores, somos políticos, fazemos política ao fazer educação. "Se sonhamos com a democracia, que lutemos, dia e noite, por uma escola em que falemos aos e com os educandos, para que, ouvindo-os, possamos ser por eles ouvidos também" (FREIRE, 1997, p.92). É preciso que os educandos, experimentando-se criticamente na tarefa de ler e de escrever, percebam as tramas sociais em que se constituem e se reconstituem a linguagem, a comunicação e a produção do conhecimento, a fazer da escola o espaço de reflexão e conscientização. "A escola, em que se pensa, em que se atua, em que se cria, em que se fala, em que se ama, se adivinha a escola que diz sim à vida. E não a escola que emudece" (FREIRE, 1997, p.63). Esta é a escola e a relação na qual o professor da EJA deve ansiar em sua atuação.

Com isso, o papel do docente é fundamental. De acordo com Moran, Masseto e Behrens (2000, p.12) “A educação é o caminho para promover a transformação da sociedade, tendo como objetivo geral articular ensino e vida, conhecimento e ética, reflexão e ação a ter uma visão de totalidade". Desta forma, o professor de ensino de EJA fará essa articulação para que o adulto se identifique com o ensino e o torne mais significativo, assim, consiga aprender com mais facilidade.

Ainda, segundo Moran (2000, p.12), “A educação é o caminho para unir todas as dimensões da vida, para que seja possível modificar a sociedade atual”. Com relação ao ensino, pode se dizer que se trata de um processo social em que o adulto deve se sentir parte integrante, ou seja, para que se promova um ensino de qualidade, preocupado com a formação integral dos indivíduos, é necessário que o professor articule ao ensino a vivência do cidadão em sociedade. Assim, cabe ao professor organizar o que considera pertinente para a construção desses valores, como "[...] ideias e atitudes, tendo por base alguns eixos fundamentais comuns como a liberdade, a cooperação e a integração pessoal" (MORAN, 2000, p.31). Torna-se necessário em sua prática estabelecer uma relação de aproximação com seus educandos, a incluir respeito e confiança mútua. Sobre a relação do conhecimento e do aprendizado, Freire (1997) afirma:

O aprendizado do ensinante, ao ensinar, se verifica na medida em que o ensinante, humilde, aberto, se ache permanentemente disponível a repensar o pensado, rever-se em suas posições; em que procura envolver-se com a curiosidade dos educandos e os diferentes caminhos e veredas que ela os faz percorrer (FREIRE, 1997, p.19). 
Sobre o trabalho do professor, Freire $(1997$, p.9) enfatiza a tarefa do ensinante, que requer comprometimento e gosto "de querer bem não só aos outros, mas ao próprio processo que ela implica". Por sua vez, sobre a impossibilidade de ensinar sem ousar, comenta:

Ousar para falar em amor, para estudarmos, aprendermos, ensinarmos e conhecermos com o nosso corpo inteiro, para jamais dicotomizar o cognitivo do emocional, para ficar ou permanecer ensinando por longo tempo nas condições que conhecemos, mal pagos, depreciados e resistindo ao risco de cair vencidos pelo cinismo (FREIRE,1997, p.10).

Dessa forma, o trabalho educativo entre professor e educando propicia maior interação, pois permite conhecer, ouvir e entender o que os educandos pensam e sentem. Freire (1997) afirma que "É importante vivermos a experiência equilibrada e harmoniosa, entre falar ao educando e falar com ele" (FREIRE, 1997, p.58), compreendendo, assim, suas reais necessidades.

Ainda de acordo com o Freire (1997), o ensinante também deve ser aprendiz, já que é preciso ousadia ao próprio fato de se fazer professor, educador, que se vê responsável profissionalmente pela formação permanente. Assim, discutimos as possibilidades de atuação docente na EJA, que tem como base a aprendizagem escolar, como também a aprendizagem social.

\section{Considerações finais}

O professor no contexto da EJA apresenta papel fundamental e de grande relevância, pois atua como mediador do conhecimento científico, assim como tem um compromisso ético e social com os educandos, uma vez que, ao mediar os conceitos científicos, à luz das experiências sociais já estabelecidas, permite aos alunos um olhar diferenciado dos fenômenos sociais que o cercam e por conseguinte, atuações conscientes e fidedignas às demandas do seu contexto social.

É importante considerar que a construção do sujeito como cidadão político participativo não cabe estritamente à educação escolar. Contudo, o processo educativo e, principalmente, o trabalho do professor em sala de aula possibilitam condições de crescimento para além da simples aprendizagem de leitura e escrita, mas, também, a construção de uma consciência crítica 
necessária à participação social. Assim, é possível aos indivíduos elaborar e expressar suas reflexões e conhecimentos sobre diversos assuntos durante o processo formativo de escolarização.

O cidadão deve ser estimulado a praticar sua cidadania em todos os momentos de sua vida, não apenas em determinados situações ou atividades sociais. Uma das possibilidades de atuação docente na EJA é oferecer aos jovens e adultos instrumentos políticos, e conhecimentos é um deles, para a ação interativa na sociedade, porque à medida que recebe os conhecimentos age sobre ela. Por outro lado, um limite que o educador encontra nesse contexto é a falta de recursos, infra-estrutura e outros problemas de cunho político que interferem em seu trabalho, dessa forma, é necessário que se tenham políticas públicas voltadas a educação que contemplem esses aspectos.

Verificamos também, que no ensino de jovens e adultos há pessoas que nunca frequentaram a escola e outros que têm algum nível de escolarização, mas em ambos os casos, os educandos necessitam dos estudos. O nível de escolaridade e alfabetização varia, porém todos os educando matriculados na EJA necessitam de auxilio pedagógico e incentivo pessoal para que consigam aprender efetivamente e concluir seus estudos com êxito, e nesse contexto, necesita do trabalho do professor, para além do processo ensino e aprendizagem do conteúdo escolar.

As discussões aqui expostas revelam que muitos são os motivos para que um adulto ou jovem volte para escola, dentre eles se destaca a necessidade de ler e escrever. Por estar inserido em uma sociedade letrada, jovens e adultos buscam o aprendizado para tentar suprir necessidades próprias, sejam elas profissionais ou pessoais, e o professor possibilita ao aluno o acesso à leitura e à escrita não apenas como um aprendizado escolar mas como um importante mecanismo social, no qual levará o educando a reflexão e conscientização do seu lugar no mundo, do seu papel em sociedade, e da importância do conhecimento.

Ao retornarem à escola, jovens e adultos pretendem não apenas iniciar ou retomar seus estudos, mas conseguir concluí-los com êxito, porém, nem sempre conseguem. Há, nesse contexto, diversas dificuldades no processo de aprendizagem e alfabetização, por exemplo, currículo e metodologia que não atendem às especificidades da faixa etária a que se destinam; problemas da vida cotidiana; dificuldade no processo de ensino-aprendizagem, entre outros. Um 
desses fatores, também, pode ser a falta de vínculo com o professor e o ensino, fatos esses que se caracterizam como um limite na atuação docente da EJA. Dessa forma, um trabalho adequado à faixa etária e um currículo pensado e elaborado para esses alunos juntamente com o trabalho docente permitem o ensino e a aprendizagem efetiva para educandos de EJA.

Afirmamos que a ação docente na EJA abrange importantes aspectos na vida nos educandos, não apenas no que se refere ao conteúdo escolar, mas também ao acesso a outras culturas, ao conhecimento, ao resgate social e a possibilidade de ampliar o papel de jovens e adultos não escolarizados em sociedade, na qual por meio da educação reflitam sobre fatos que antes não tinham consciência. Já os limites estão nas especificidades próprias da modalidade, na qual exigem que o docente tenha um olhar diferenciado para esses educandos, e que busque por meio de seu trabalho realizar uma prática libertadora das amarras sociais, as quais não possibilitam aos indivíduos desenvolver o que a educação tem de excelência: a liberdade de pensar livremente. Além disso, há questões políticas que podem limitar prática docente como a falta de recursos, incentivo do governo, contratação de pessoas especializadas para realizarem esse trabalho.

A EJA é uma importante modalidade educacional que abrange aspectos tanto pedagógicos e formativos, como também sociais e de cidadania. Nela, o docente deve buscar ampliar as possibilidades de estudo e também de vida de seus estudantes, por meio de um ensino planejado, elaborado e que contemple os aspectos necessários para a construção de uma sociedade mais democrática a valorizar os saberes adquiridos socialmente.

\section{Referências}

ANDRADE, E. R. Os jovens da EJA e a EJA dos jovens. In: OLIVEIRA, I. B.; PAIVA, J. (orgs.). Educação de jovens e adultos. Rio de Janeiro: DP\&A, 2004, p.43-54.

BRASIL. Lei n.9394/1996 - Lei de Diretrizes e Bases da Educação Nacional. Brasília: Ministério da Educação, 1996.

BRASIL. Ministério de Educação e Cultura. Parecer CEB 11/2000. Diretrizes curriculares nacionais para a educação de jovens e adultos. Brasília: MEC, 2000.

BRASIL. MEC. Documento Base Nacional. Desafios da educação de jovens e adultos no Brasil: sujeitos da educação de jovens e adultos. Brasília: Ministério da Educação, 2008. 
BRASIL. Diretrizes Curriculares Nacionais da Educação Básica. Brasília: Ministério da Educação, 2013.

BRASIL. Lei n.13.005. Plano Nacional de Educação. Diário Oficial da União, Brasília, 26 jun 2014. Disponível em:< http://www.planalto.gov.br/ccivil_03/_Ato2011-2014/2014/Lei/L13005.htm>. Acesso em: 30 dez. 2020.

BRASIL. Base Nacional Comum Curricular. Brasília: Ministério da Educação, Conselho Nacional de Educação, 2017.

BRASIL. Indicador de alfabetismo funcional. Instituto Montenegro, São Paulo: 2018.

DI PIERRO, M. C.; JOIA, O.; RIBEIRO, V. M. M. Visões da educação de jovens e adultos no Brasil. Cadernos CEDES, Campinas, v.21, n.55, p.58-77, nov. 2001. Disponível em:

<https://www.scielo.br/pdf/ccedes/v21n55/5541.pdf>. Acesso em: 13 ago. 2020.

DIAS, F. V. et al. Sujeitos de mudanças e mudanças de sujeitos: as especificidades do público da educação de jovens e adultos. In: SOARES, L. (org.). Aprendendo com a diferença: estudos e pesquisas em educação de jovens e adultos. Belo Horizonte: Autêntica, 2011, p.49-82.

DURANTE, M. Alfabetização de adultos: leitura e produção de textos. Porto Alegre: Grupo A, 1998. FERREIRO. E. Alfabetização em processo. 21. ed. São Paulo: Cortez, 2015.

FREIRE, P. Educação e mudança. 12. ed. Rio de Janeiro: Paz e Terra, 1979.

FREIRE, P. Sobre educação, vol.1. Rio de Janeiro: Paz e Terra, 1982.

FREIRE, P. Pedagogia da autonomia: saberes necessários à prática educativa. São Paulo: Paz e terra, 1996.

FREIRE, P. Professora sim, tia não: cartas a quem ousa ensinar. São Paulo: Olho d'água, 1997.

FREIRE, P. A importância do ato de ler. 41. ed. São Paulo: Cortez, 2001.

HADDAD, S.; DI PIERRO, M. C. Escolarização de jovens e adultos. Revista Brasileira de Educação, n.14, p.108-130, maio/ago. 2000. Disponível em:

<https://www.scielo.br/pdf/rbedu/n14/n14a07>. Acesso em: 13 ago. 2020.

KUENZER, A. Z. Ensino médio: construindo uma proposta para os que vivem do trabalho. São Paulo: Cortez, 2002.

LUDKE, M; ANDRÉ, M. Pesquisa em educação: abordagens qualitativas. São Paulo: EPU, 1986. 
MACIEL, K. F. O pensamento de Paulo Freire na trajetória da educação popular. Educação em Perspectiva, Viçosa, v.2, n.2, p.326-344, 2011. Disponível em:

$<$ https://periodicos.ufv.br/educacaoemperspectiva/article/view/6519/2677>. Acesso em: 13 ago. 2020.

MARCHESONI, L. B. Letramento e educação escolar: um estudo com educandos da educação de jovens e adultos.2019.146f. Dissertação (Mestrado em Educação) - Universidade Estadual de Maringá, Maringá, 2019.

MARTINELLI, S. C. Um estudo sobre desempenho escolar e motivação. Educar em Revista, Curitiba, Brasil, n.53, p.201-216, jul./set. 2014. Disponível em:

<https://www.scielo.br/pdf/er/n53/13.pdf>. Acesso em: 13 ago. 2020.

MORAN, J. M.; MASETTO, M. T.; BEHRENS, M. A. Novas tecnologias e mediação pedagógica. Campinas: Papirus, 2000.

OLIVEIRA, M. K. Jovens e adultos como sujeitos de conhecimento e aprendizagem. Revista Brasileira de Educação, São Paulo, v.12, p.59-73, 1999. Disponível em:

<http://eixovpsicologia.pbworks.com/f/texto+6.pdf>. Acesso em: 13 ago. 2020.

OLIVEIRA, I. B. Reflexões acerca da organização curricular e das práticas pedagógicas na EJA. Revista Educar, n.29, p.83-100, 2007. Disponível em:

<https://www.scielo.br/pdf/er/n29/07.pdf>. Acesso em: 13 ago. 2020.

PAIVA, J. Educação de jovens e adultos: direito, concepções e sentidos. 2009. 482f. Tese (Doutorado em Educação) - Programa de Pós-Graduação em Educação da Universidade Federal Fluminense. Niterói: UFF, 2009.

PARANÁ. Diretrizes Curriculares da Educação de Jovens e Adultos. Secretaria de Estado da educação. Curitiba: 2006.

PINTO, A. V. Sete lições sobre educação de adultos. São Paulo: Autores Associados/Cortez, 1982.

SCHWARTZ, S. Alfabetização de jovens e adultos. Petrópolis: Vozes: 2012.

SHIMAZAKI, E. M.; CÁRNIO, M. S. Letramento e alfabetização das pessoas com deficiência intelectual. Revista Teoria e Prática da Educação, v.14, n.1, p.143-151, jan.-abr. 2011. Disponível em: <http://periodicos.uem.br/ojs/index.php/TeorPratEduc/article/view/16112/8720>. Acesso em: 13 ago. 2020.

VISCA, J. O diagnóstico operatório na pratica psicopedagógica. São José dos Campos: Pulso, 2008.

VYGOTSKY, L. S. Obras escogidas. Madrid: Visor, 1996. 
Recebido em fevereiro 2020.

Aprovado em novembro 2020. 